JRRD

\title{
Depression and experience of vision loss in group of adults in rehabilitation setting: Mixed-methods pilot study
}

\author{
Hugo Senra, PhD; ${ }^{1^{*}}$ Cristina R. Vieira, MA; ${ }^{2}$ Elizabeth G. Nicholls, MIT; ${ }^{3}$ Isabel Leal, PhD ${ }^{\mathbf{4}}$ \\ ${ }^{1}$ University of Deusto, Faculty of Psychology, Bilbao, Spain; ${ }^{2}$ University of Santiago de Compostela, Faculty of Psychology, \\ Santiago de Compostela, Spain; ${ }^{3}$ Department of Psychology, Drexel University, Philadelphia, PA; ${ }^{4}$ ISPA, Instituto Universi- \\ tário, Uipes-I\&D, Lisbon, Portugal
}

\begin{abstract}
There is a paucity of literature regarding the relationship between the experience of vision loss and depression. Therefore, the current pilot study aimed to explore whether significant differences existed in levels of depression between adults with different vision loss experiences. A group of adults aged between 20 and 65 yr old with irreversible vision loss in a rehabilitation setting was interviewed. Semistructured interviews were conducted in order to explore patients' experience of vision loss. The Center for Epidemiologic Studies Depression Scale (CES-D) was used to assess depressive levels; $39.5 \%(n=15)$ of patients met CES-D criteria for depression. In addition, higher levels of depression $(p<0.05)$ were identified in patients whose interviews revealed greater selfawareness of impairment, inadequate social support, and longer rehabilitation stay. Current findings draw attention to variables such as self-awareness of impairment and perceived social support and suggest that depression following vision loss may be related to patients' emotional experiences of impairment and adjustment processes.
\end{abstract}

Key words: depression, experience, mixed-methods, qualitative, rehabilitation, self-awareness, self-identification, social support, vision loss, well-being.

\section{INTRODUCTION}

Irreversible vision loss is a highly impairing condition that often comprises a set of changes and losses hard to overcome. As such, high levels of emotional distress, particularly depressive symptomatology, have been identified in adults diagnosed with irreversible vision loss [1-4]. For example, older adults with visual impairment are at increased risk for depression as compared with their nondisabled peers [5-6]. The prevalence of depression among elderly people with irreversible vision loss varies between 25 and 45 percent [7-9]. These values are above what is expected for the general population. A recent study indicated that approximately 15 percent of the adult population in high-income countries would meet criteria for a major depressive episode during their lifetime [10]. Unfortunately, depression following irreversible vision loss in elderly individuals is associated with poor general functioning [11-14], long-term emotional distress [1,3], problems with well-being [15-16], poor quality of life [17-18], and problems in health and social participation [19]. In fact, some studies have reported that depression following vision loss represents a secondary source of disability [20-21].

Although elevated rates of depression have been identified in individuals with loss of vision, evidence suggests that psychological dysfunction is not directly related to severity of visual impairment. For example, a recent study

\footnotetext{
Abbreviation: CES-D = Center for Epidemiologic Studies Depression Scale.

*Address all correspondence to Hugo Senra, PhD; University of Deusto, Faculty of Psychology, Avenida de las Universidades 24, 48007 Bilbao, Spain; +34-94-413-90-00, ext 2768. Email: hugo senra@hotmail.com

http://dx.doi.org/10.1682/JRRD.2012.08.0138
} 
by Dreer et al. identified no direct association between visual acuity and depression [22]. Rather, higher levels of emotional distress were found in patients with less tolerance of vision loss as well as in those who perceived a greater interference of vision loss with their goal-directed behavior and expected activities. Similarly, Tabrett and Latham reported that adjustment to impairment was associated with depression among adults with irreversible vision loss, but significant relationships between depression, severity/duration of vision loss, and self-reported functional limitations were not identified [23]. In that study, the assessment protocol for the severity of vision loss took into account the patients' visual acuity, contrast sensitivity, reading performance, and visual fields.

Several researchers have also investigated relationships between depression and other psychological variables in adults with vision impairment, identifying higher rates of depression in patients who reported loneliness, fear of dependence, lack of self-worth, and feelings of changes in their own identity $[16,24]$. Other studies have associated maladaptive coping strategies, such as emotionfocused coping and a ruminative coping style, with greater levels of emotional distress and adjustment problems in those with visual impairment [25-27]. However, the vast majority of studies investigating psychological outcomes related to vision loss have focused exclusively on elderly individuals (older than 65). Researchers have only begun to investigate the experiences of visually impaired younger adults, who may face unique challenges.

Recent studies have revealed that among young and middle-aged adults, loss of vision tends to affect a wide range of life domains that may be less salient to elderly individuals with vision loss [28-29]. More specifically, young and middle-aged adults tend to report a great number of life changes related to vision loss, including disruptions in social relationships, difficulties returning to work, and changes in self-perception [28-29].

A recent qualitative study also investigating the experiences of young and middle-aged adults with vision loss identified four core themes: self-awareness of impairment, self-identification with impairment, perceived social support, and perceived well-being [30]. The extant literature thus suggests that vision loss in early adulthood or middle age may negatively affect important life domains (e.g., employment) that have been largely ignored in research focused on the elderly. Moreover, given that levels of depression in those with visual impairment have been associated with greater interference with goal-directed behavior, functional limitations, and fears of dependence on others in elderly samples [17,24-26,28-29], it is reasonable to suspect the psychological impact of vision loss on younger individuals may be considerable. However, to our knowledge, no research has investigated the relationship between the phenomenon of depression and the experience of vision loss in young and middle-aged adults.

The goal of the current pilot study is to explore whether differences exist in levels of depression between middle-aged and young adults with different vision loss experiences, as part of a larger research project concerning psychological outcomes of vision loss in adulthood [31]. More specifically, the first part of the project [30] was aimed at exploring the experience of vision loss in young and middle-aged adults (20 to $65 \mathrm{yr}$ old) in order to identify the core themes related to patients' experiences of vision loss. The second part, the present study, explores possible associations between the previously identified core themes (i.e., self-awareness of impairment, selfidentification with impairment, perceived social support, and perceived well-being) and depressive levels. The present study targets the investigation of psychological outcomes in young and middle-aged adults with vision loss and, as such, represents a first step in determining whether treatment needs in this population differ from those of elderly individuals with visual impairment.

\section{METHODS}

In order to explore the relationship between previously identified core themes on patients' experiences of vision loss and levels of depression, a mixed-methods approach with a convergent parallel design [32-33] was adopted. In this design, qualitative (core themes of the adults' experiences of vision loss) and quantitative data (levels of depression, clinical data) were collected concurrently, analyzed separately, and then merged [32]. As shown in the Figure, the current mixed-methods study aimed to compare depressive levels among patients with different vision loss experiences to determine whether significantly different levels of depression would be identified between patients with more and less selfawareness of impairment, self-identification with impairment, perceived social support, and perceived well-being. In addition, levels of depression were also compared between patients presenting with different vision loss characteristics, such as patients with low vision versus blindness, and patients with different lengths of stay in rehabilitation. 


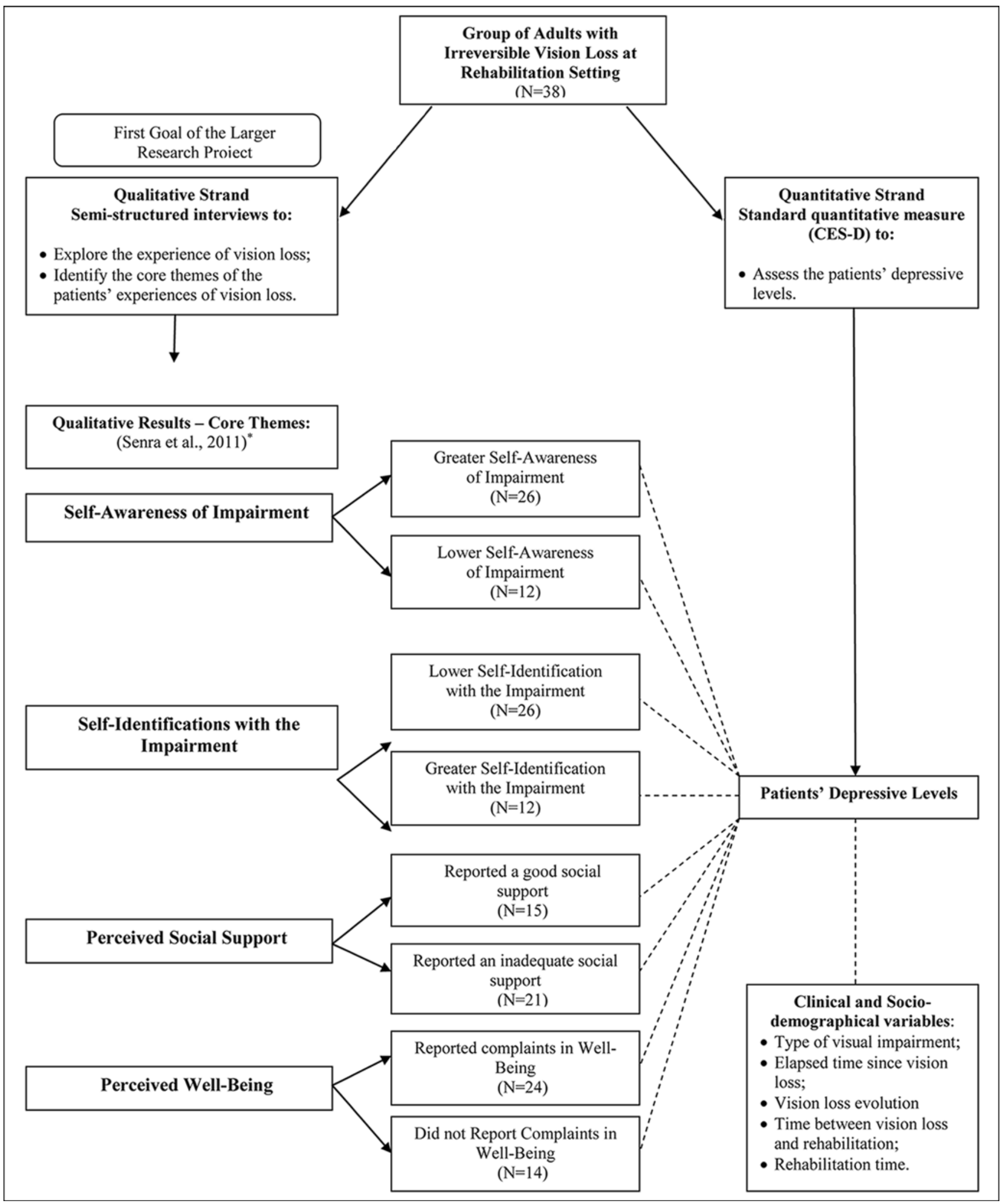

Figure.

Mixed-methods research design structure. CES-D = Center for Epidemiological Studies Depression Scale. *Senra H et al. [30]. 


\section{Sample}

The sample was composed of 38 young and middleaged adults recruited from two rehabilitation centers for adults with acquired visual impairment. Inclusion criteria stated that participants must be between 20 and $65 \mathrm{yr}$ old and have experienced vision loss after the age of $18 \mathrm{sec}-$ ondary to an ophthalmological disease or eye trauma. In addition, all patients were required to be in a rehabilitation setting at the time of data collection. All participants were diagnosed with severe visual impairment or blindness according to World Health Organization [34] criteria, which consider a visual impairment to be severe when visual acuity is worse than $6 / 60$ and equal or better than $3 / 60$ in the better eye with the best correction, or when the visual field is less than $10^{\circ}$ from the point of fixation. Blindness is considered to exist when visual acuity is worse than 3/60 in the better eye with the best correction and with a visual field less than $10^{\circ}$.

Patients were excluded if self-report revealed congenital visual impairment, history of medical comorbid conditions not directly related to vision loss, history of psychological disorders before vision loss, or history of long-term psychiatric medication other than occasional anxiolytics for sleeping disorder. Severity of visual impairment was previously assessed by a specialized ophthalmologist. Health and psychological status had been previously assessed by the rehabilitation center staff using standardized tests to screen for psychological disorders (Beck Depression Inventory, Minnesota Multiphasic Personality Inventory). The rehabilitation center staff, who were aware of the study's eligibility criteria, performed the first selection of our sampling.

The rehabilitation centers from which patients were drawn consist of interdisciplinary programs focused on enhancing daily life skills (e.g., being able to walk, dress, cook, write, and read without assistance) and restoring independence. In these programs, patients are also encouraged to be socially active, as well as to participate in sports and engage in artistic activities. Patients from all Portuguese provinces were eligible to attend programs in this rehabilitation center. The rehabilitation program provides a wide range of integrated care services, including psychological treatment, mobility and orientation classes, activities of daily living, psychomotricity (which is defined as a therapy based on interactions between individual's cognitive, emotional, symbolic, and physical functioning and whose goal is to promote the capacity to function in a psychosocial context as essential to individuals' overall well-being and reha- bilitation [35]), braille, computer-adapted technologies, and art therapy. Each patient's rehabilitation program is discussed by all rehabilitation staff members to identify priority areas to be worked on and to adjust the program to the patient's needs. A close relationship with the patients' families is also provided to promote patients' social and emotional support and to provide their families with counseling. These rehabilitation programs are designed to last 4 mo, but may be exceptionally extended in order to meet some particular patients' needs and outcomes, such as the need to be psychologically prepared to learn how to use the white cane or to learn braille. Optometry and specialized ophthalmology are provided to all patients through a partnership with the rehabilitation center and the low vision unit of an ophthalmological public hospital and with the ophthalmological department of a general public hospital.

Thirty-eight patients participated in the current study. Patients' mean age was 42.7 yr. The majority of patients were between 36 and 65 yr of age (73\%), had less than $10 \mathrm{yr}$ of education (74\%), and were blind (66\%). Participants' mean age at vision loss was 39, and the most frequent cause of visual impairment was glaucoma (34\%). Twenty patients (52\%) had lost their vision 2 yr or less before the time of data collection, while eighteen patients (48\%) had experienced vision loss more than 2 yr before data collection. In terms of the length of rehabilitation period, the majority of patients (86\%) were in rehabilitation for 6 mo or less. For a complete list of demographic characteristics, see Table 1.

\section{Data Collection}

Qualitative data regarding the experience of vision loss was collected using a semistructured interview that utilized open-ended questions focused on patients' general experience of vision loss [30]. Clinical data were collected through a brief questionnaire. Levels of depression were assessed using the Center for Epidemiologic Studies Depression Scale (CES-D) [36]. The CES-D is a selfrating scale, with a final score that ranges from 0 to 60 . A cut-off score of 23 was defined for CES-D according to the Portuguese version of the instrument.

Data were collected during two audio-recorded interviews per patient, lasting between 45 and 60 min each. Two interviews were conducted with each patient because our previous experience with these patients suggested that single interviews were not sufficient to collect comprehensive data regarding an individual's experiences of vision loss. In a few cases, individual patients' rehabilitation 
Table 1.

Characterization of sample.

\begin{tabular}{|c|c|c|}
\hline Variable & $n(\%)$ & Mean \pm SD (Min, Max) \\
\hline Age (yr) & & $42.7 \pm 14.5(20,64)$ \\
\hline 20-35 & $14(37)$ & \\
\hline $36-65$ & $24(73)$ & \\
\hline \multicolumn{3}{|l|}{ Sex } \\
\hline Male & $20(53)$ & \\
\hline Female & $18(47)$ & \\
\hline \multicolumn{3}{|l|}{ Education Level (yr) } \\
\hline Up to 9 & $28(74)$ & \\
\hline$>9$ & $10(26)$ & \\
\hline Age at Vision Loss (yr) & & $39.2 \pm 14.0(18,64)$ \\
\hline $18-35$ & $17(45)$ & \\
\hline $36-65$ & $21(55)$ & \\
\hline \multicolumn{3}{|l|}{ Acquired Visual Impairment Type } \\
\hline Blindness & $25(66)$ & \\
\hline Severe Low Vision & $13(34)$ & \\
\hline \multicolumn{3}{|l|}{ Main Pathologies Causing Vision Loss } \\
\hline Glaucoma & $13(34)$ & \\
\hline Retinitis Pigmentosa & $7(18)$ & \\
\hline Retinopathy & $7(18)$ & \\
\hline Physical Trauma & $3(8)$ & \\
\hline Cataracts & $2(5)$ & \\
\hline Myopia & $2(5)$ & \\
\hline Others & $4(11)$ & \\
\hline Time Between Vision Loss and Interviews (yr) & & $3.3 \pm 2.9(1,16)$ \\
\hline $0-2$ & $20(52)$ & \\
\hline$>2$ & $18(48)$ & \\
\hline \multicolumn{3}{|l|}{ Vision Loss-Related Comorbid Diagnoses ${ }^{*}$} \\
\hline Diabetes Mellitus & $12(32)$ & \\
\hline Rehabilitation Time (mo) & & $4 \pm 3(1,12)$ \\
\hline $0-6$ & $32(86)$ & \\
\hline$>6$ & $6(14)$ & \\
\hline
\end{tabular}

schedules required the interview to be broken up into three parts. All interviews were conducted by a psychologist experienced in interviewing adults with vision loss. A total of 87 interviews were conducted. Ethical procedures were adopted following the institutional protocol (Instituto de Oftalmologia Dr. Gama Pinto) and by the use of an informed consent form.

\section{Qualitative Data Analysis}

Qualitative data analysis was based on the thematic and categorical analysis proposed by Bardin [37]. As such, an inductive analysis modality using an open coding technique was adopted [38-39] to avoid any preconceptions about the subjects. Main content analysis was conducted as follows: transcriptions were read in order to infer the specific meanings and structure, specific meanings that generated open codes (semantic criteria) were identified and labeled, codes sharing common themes were gathered, themes were reanalyzed and reviewed for labeling and regrouping in thematic categories, and finally, thematic categories were validated by reassessing patients' direct quotations. All coding was performed independently by two researchers. These researchers conducted an exhaustive discussion and reflection on each 
meaning and defined criteria for each theme's categorization at all steps of analysis, such that identification process of themes and categories resulted from the consensus between the researchers. Disagreements were resolved by repeated discussion of each transcript until the two researchers achieved consensus.

\section{Independent Variables for Mixed-Methods Design}

\section{Qualitative Variables}

Results from the previous qualitative study [30] indicated four core themes on the experience of vision loss: self-awareness of impairment, self-identifications with the impairment, perceived social support, and perceived well-being. These core themes were extracted based on Bardin's thematic analysis and codification system [37]. In each core theme, two subthemes were identified. Qualitative independent variables are subsequently described in detail and illustrated with quotations [30].

Self-awareness of impairment. Patients were asked to express the extent to which they found visual impairment to interfere in their lives. Some patients $(n=26)$ verbalized feelings and emotions related to becoming visually impaired and showed emotional responsiveness related to the impairment. The feelings most commonly noted by patients were sadness, depression, anguish, anxiety, shock, difficulty with accepting impairment, and thoughts of death. In addition, patients also reported life changes caused by vision loss, mainly related to basic daily life skills, employment, driving, identity/personality, psychological well-being, quality of life, and romantic relationships. Patients who acknowledged rehabilitation needs, lifestyle changes, and future functional restrictions (e.g., having to stop driving) were considered to have greater self-awareness of impairment as they specifically recognized visual impairment as necessitating significant changes in their lives. In other words, these patients were fully aware of their current situation, did not minimize or deny impairment, and were willing to make the necessary adjustments in their lives. The following quote illustrates a case of a patient considered to have greater self-awareness of impairment.

I went through a period of serious depression. I did not want to see the reality . . . I isolated myself . . . I started to drink ... It was very painful ... to have to quit work and losing my independence. I realized that this situation was changing everything around me, because my life would not be the same again. (Patient 15)

In contrast, a substantial proportion of patients $(n=$ 12) evidenced difficulty in appraising the effect of vision loss in their lives. These patients reported little or no emotional responsiveness regarding the situation of becoming visually impaired, and some also rationalized the negative interference of vision loss in their lives and showed some unrealistic expectations. In addition, these patients minimized daily life changes caused by the impairment and devalued the importance of rehabilitation for their future. Because this group did not find visual impairment to have produced significant life changes, they were considered to have less self-awareness of the impairment. Notably, these characteristics were identified in patients at different times after vision loss. The following quote illustrates a case of a patient considered to have lower self-awareness of impairment.

No, I didn't feel like I was depressed or feeling down! I am a strong person! I had to give up some business, but I have other plans. Once my rehabilitation is complete I will undertake some business and investments on real estate! Actually I cannot waste any more time . . . Here in the rehabilitation we waste a lot of time, and time is money! (Patient 10)

Self-identification with impairment. During the interview, patients were also prompted to express the extent to which they considered visual impairment to be part of their identity. Twelve patients described themselves as being blind or as having low vision, evidencing selfidentification as a visually impaired individual. These patients also demonstrated behaviors such as having a good relationship with peers in rehabilitation, acknowledging the importance of performing lifestyle changes, valuing the role of rehabilitation in their future life, and showing willingness to train with assistive devices (e.g., using a cane and learning braille). Some patients in this group also reported having future life plans following the successful rehabilitation program, such as studying or returning to work. Because this group of patients thus manifested greater acceptance of impairment, rehabilitation-related tasks, and assistive devices, they were considered to have greater self-identification with the impairment. The following quote illustrates a case of a patient considered to have greater selfidentification with the impairment. 
At the beginning [of the rehabilitation] I hid my situation from others and refused to accept the white stick! I felt ashamed because I did not want to be looked at as blind! Now I accept it. I know I needed to go through that resistance. Now I am inseparable of my cane. It has allowed me to start walking again, and to become more independent from others. I am very thankful to my mobility teacher! . . . I am also planning to return to study ... There are incredible things we can do after becoming blind. I have also learned how to cook. (Patient 37)

In contrast, some patients $(n=26)$ showed difficulty in considering visual impairment as part of themselves. These patients have demonstrated a set of behaviors including resistance or lack of willingness in learning to use assistive devices, managing daily life activities, and making lifestyle changes required by vision loss. This group of patients also tended to maintain ambivalent or negative relationships with peers and sometimes expressed their intention to refuse the rehabilitation program. Some of these patients also verbalized resistance or avoidance of accepting the irreversible nature of their vision loss, sometimes mentioning their hopefulness in further medical treatment. This group of patients was considered to have less self-identification with their impairment, manifesting poor acceptance of altered abilities as well as disinterest in rehabilitation-related tasks and assistive devices. The following quote illustrates a case of a patient considered to have less self-identification with the impairment.

I avoid talking about my vision loss to others, especially to my family and friends. It is still hard for me to face others ... and me ... I'm a different person! I can't see myself as being blind! I know that the rehabilitation could be important for me, but I still experience some troubles with the stick. It is hard for me to imagine myself walking down the street with the cane! Definitely it is too soon for that! (Patient 14)

Perceived social support. In addition to impairments in self-awareness and self-identification as impaired, one of the core interview topics also referred to the way that patients perceived their current social support. These questions prompted patients to describe the extent to which they were satisfied with their current family, friends, and community support resources. The majority of patients $(n=21)$ reported dissatisfaction with the support they were receiving from family, friends, or community. Most of these patients reported perception of inadequate family support or feeling abandoned by family and/or friends, thus describing insufficient support in facing daily challenges caused by the impairment. Some of these patients $(n=10)$ also reported being subjected to social and family discrimination secondary to their visual impairment. As such, this group of patients was considered as having perceptions of inadequate social support. The following quote illustrates a case of a patient in this group.

My mother does not understand that I need to be more independent. She is always overprotective. It was very hard for me to convince her to let me go to the rehabilitation. She felt it would be dangerous for me. She is always blocking me! I need more space! (Patient 1 )

However, other patients $(n=15)$ reported good and helpful social support. These patients described their family, friends, and/or community as being crucial to being able to cope with vision loss, overcoming daily challenges and keeping them motivated for the rehabilitation program. Some of these patients also associated family support with their achievements related to functional recovery and social reintegration. As such, this group of patients was considered as having perceptions of good social support. The following quote illustrates the case of such a patient.

My husband and sons have been precious to me! If it weren't for their help I could have never had handled this situation! My friends have also been precious! They are always trying to make me feel more comfortable with my vision loss. It is important because sometimes I feel like others look at me in a different way! (Patient 32)

Perceived well-being. Another core interview topic was related to the way patients perceived their current wellbeing in activities of daily living. This topic was intended to explore the extent to which patients experienced physical and psychological complaints besides the visual impairment. The majority $(n=24)$ reported physical and/ or psychological complaints such as pain, sleep disturbances, depression, loneliness, phobias, and feelings of social discrimination. This group of patients was considered to perceive their general well-being as comprising some relevant complaints, because they reported several physical and/or psychological problems that negatively 
interfered in their lives. The following quote illustrates a case of a patient who reported several complaints regarding his/her well-being:

I have experienced some problems with the opposite sex. I would like to have more female friends, but I am very ashamed. Moreover, I feel like they do not want to meet me because I have some troubles in seeing people. Moreover I am feeling bad. I have experiencing difficulties to sleep ... I I have had headaches ... I think I have to make some changes in my life to better overcome my current situation. (Patient 3 )

In contrast, some patients $(n=14)$ reported no physical and/or psychological complaints besides visual impairment. This group of patients was considered to perceive their general well-being as not comprising any complaints, because they reported no physical and/or psychological complaints capable of negatively interfering in their lives.

\section{Clinical Variables}

In the current mixed-method design, some quantitative variables related to patients' clinical history were investigated for relationships with levels of depression. These variables consisted of type of acquired visual impairment (low vision vs total blindness), elapsed time between the first diagnosis of a serious ophthalmological disorder and the moment in which the patient became formally visually impaired (vision loss evolution), time since vision loss, time between vision loss and beginning rehabilitation, and length of rehabilitation period. These variables were selected for analysis because of their potential influence on levels of depression.

\section{Statistical Data Analysis}

The strategy adopted for statistical analysis considered the size of the current study's sample, taking into account the number of subjects included in each group. Theoretically, the adoption of a multivariate model would allow for exploration of how each variable relates to depression, as well as how they interrelate with one another. However, the current sample size was not sufficient to produce reliable results with acceptable statistical power [40-41]. Therefore, a more simplistic analysis was adopted, in line with previous research with a similar sample and design [42]. In order to produce reliable results, this statistical option is only intended to explore possible significant differences in levels of depression between groups and correlations between depression and clinical variables.

Parametric tests with a 95 percent confidence interval were utilized considering the normal distribution and the homogeneity of the variances of our dependent variable (levels of depression) among groups. Pearson correlation tests (two-tailed) were used to correlate CES-D scores with quantitative independent variables (time since vision loss, vision loss evolution, time between vision loss and beginning rehabilitation, and length of rehabilitation). The purpose of these correlations was to explore the potential relationships between depression and some clinical variables. The Student $t$-test was selected to compare mean scores of CES-D for each independent categorical variable (type of acquired visual impairment [low vision vs total blindness], self-awareness of impairment, self-identification with impairment, perception of social support, and perception of well-being). The $t$-test was also used to compare the elapsed time since patients lost their vision among patients with greater and less selfawareness of impairment, with the goal of exploring whether self-awareness of impairment could be influenced by the elapsed time since vision loss.

\section{RESULTS}

Data analysis indicated that a considerable proportion of patients ( $n=15$; 39.5\%) scored above 23 on the CES-D and thus met criteria for depression. Results for all independent variables did not violate the assumptions of normality, linearity, and homoscedasticity, and therefore, Pearson correlations and Student $t$-test could be used. Pearson correlations (two-tailed) revealed a positive correlation between CES-D score and length of rehabilitation period $(r=0.334 ; p=0.04)$. However, significant relationships were not identified between levels of depression and time since vision loss ( $r=0.282 ; p=0.09$ ), vision loss evolution $(r=0.240 ; p=0.15)$, or time between vision loss and rehabilitation $(r=0.220 ; p=0.18)$.

Significant differences in levels of depression were identified between patients with differing levels of selfawareness $(p<0.05 ; d=0.73)$ and patients with different perceptions of social support $(p<0.01 ; d=1.099)$ (Table 2). Both analyses revealed moderate to large effect sizes [43]. No significant differences in levels of depression were identified between patients with different types of visual impairment ( $p>0.05 ; d=0.17$ ), self-identification with 
impairment ( $p>0.05 ; d=0.52$ ), or perception of well-being $(p>0.05 ; d=0.34)$. Finally, no differences in terms of time since vision loss were identified between patients with different types of self-awareness of impairment ( $p>0.05 ; d=$ 0.50) (Table 3).

\section{DISCUSSION}

The current pilot study was intended to investigate relationships between experiences of vision loss, clinical characteristics, and depressive symptomatology in young and middle-aged adults with acquired vision loss. Consistent with previous research [17-18], themes emerging from patients' narratives as well as the high frequency of depression in this sample suggest poor quality of life and dramatically altered self-perceptions following vision loss in adulthood. Furthermore, current participants reported a frequency of depression (39.5\%) similar to previous studies [6-7,9,44].

Results also draw attention to the potential effect of variables such as self-awareness of impairment, perceived social support, and length of rehabilitation stay on psychological outcomes. More specifically, higher levels of depression were identified in patients who demonstrated greater self-awareness of impairment, reported inadequate social support, and had longer rehabilitation.

Although no previous research on vision loss has focused on addressing the role that self-awareness of impairment plays in depression, studies investigating psychological outcomes in other physical impairments (e.g., orthopedic injuries and traumatic brain injuries) have explored this relationship [45-46]. In these studies, patients who reported greater awareness of their impairment and its implications also presented with higher levels

Table 2.

Differences in depression levels between each variable group.

\begin{tabular}{|c|c|c|c|c|}
\hline Variable & CES-D (mean \pm SD) & $p$-Value & $t^{*}$ & Cohen $d$ \\
\hline Acquired Visual Impairment Type & & 0.61 (TST) & -0.513 & 0.17 \\
\hline Low Vision $(n=13)$ & $20.5 \pm 13.6$ & & & \\
\hline Blindness $(n=25)$ & $18.3 \pm 12.8$ & & & \\
\hline Self-Awareness of Impairment & & $0.049(\mathrm{TST})^{\dagger}$ & 2.042 & 0.73 \\
\hline More Aware $(n=26)$ & $21.4 \pm 12.7$ & & & \\
\hline Less Aware $(n=12)$ & $12.6 \pm 11.4$ & & & \\
\hline Self-Identification with Impairment & & 0.17 (TST) & -1.717 & 0.52 \\
\hline Less Identified $(n=26)$ & $20.6 \pm 13.6$ & & & \\
\hline More Identified $(n=12)$ & $14.3 \pm 10.3$ & & & \\
\hline Perceived Social Support & & $0.003(\mathrm{TST})^{\ddagger}$ & -3.204 & 1.099 \\
\hline Good $(n=15)$ & $12.0 \pm 10.5$ & & & \\
\hline Inadequate $(n=21)$ & $24.4 \pm 12.0$ & & & \\
\hline Perceived Well-Being & & 0.30 (TST) & -1.059 & 0.34 \\
\hline Without Complaints $(n=14)$ & $15.7 \pm 14.8$ & & & \\
\hline With Complaints $(n=24)$ & $20.3 \pm 11.6$ & & & \\
\hline $\begin{array}{l}{ }^{*} \text { Elo S and Kyngäs H. [38]. } \\
{ }^{\dagger} \text { Significant differences between groups for } p \text {-val } \\
{ }^{\ddagger} \text { Significant differences between groups for } p \leq 0 \\
\text { CES-D = Center for Epidemiologic Studies Depr }\end{array}$ & $\begin{array}{l}\text {-tailed). } \\
\text { o-tailed). } \\
\text { Scale, SD = standard devi }\end{array}$ & $=$ Student $t$-test. & & \\
\hline
\end{tabular}

Table 3.

Self-awareness and elapsed time since vision loss.

\begin{tabular}{|c|c|c|c|c|}
\hline Variable & Elapsed Time Since Vision Loss (mean \pm SD) & $p$-Value & $t^{*}$ & Cohen $d$ \\
\hline Self-Awareness of Impairment & & 0.19 (TST) & 1.344 & 0.50 \\
\hline More Aware $(n=26)$ & $3.7 \pm 3.3$ & & & \\
\hline Less Aware $(n=12)$ & $2.4 \pm 1.5$ & & & \\
\hline
\end{tabular}


of early and late depression. These studies concluded that patients who assessed their impairment in a realistic way and did not deny their current condition were more likely to exhibit higher levels of depression. As in Malec et al.'s studies of outcomes in traumatic brain injury [45-46], the current pilot study suggests that patients' more realistic self-assessment of impairment might be associated with greater levels of depression following vision loss. Although vision loss is very distinct from orthopedic and traumatic brain injuries, both imply a new situation in which the patient loses functioning and acquires a permanent condition of impairment. Moreover, both conditions involve disability and the need for coping with a drastic life change. In this sense, both Malec et al.'s studies and the current study suggest that depression could appear as a response to patients' sense of loss and change related to the impairment. This sense is only possible if the patient is aware of his or her current limitations - that is, if the patient has a great self-awareness of impairment.

Conversely, current results also indicate that selfawareness of impairment is not associated with time since diagnosis (vision loss). This suggests the possibility that patients' self-awareness of impairment could be more intimately related to the way patients experience the impairment, rather than being merely associated with time. This finding is consistent with a recent study that suggested that the adjustment process to vision loss and depression is associated with psychological variables such as neuroticism and conscientiousness, rather than duration and severity of the vision loss [23].

Consistent with other studies investigating psychological outcomes following vision loss [17,47-48], the current results indicated higher levels of depression within the group of patients who appraised their social support as inadequate or overprotective, as compared with patients who felt they have good social support. As such, patients' perceived social support appears to present a potential mediator of depression following vision loss and, as such, is a variable that should be taken into account in further research. Moreover, patients' perceived social support should also be considered in rehabilitation assessment protocols. Specifically, in psychotherapeutic work it should be kept in mind that lower perceived levels of social support may interfere with the patients' outcome.

Regarding patients' length of stay in rehabilitation, the present study found greater levels of depression in individuals with a longer period of rehabilitation (more than $4 \mathrm{mo}$ ), whereas some previous studies have found a posi- tive effect of rehabilitation on patients' emotional distress [49-50]. Thus, current results are at odds with the previous literature. Given that in the rehabilitation setting patients are usually encouraged to socially interact with peers and face a set of functional limitations, rehabilitation may also promote patients' awareness of the impairment. In this sense, the presence of greater levels of depression in these patients could be explained by the effect that rehabilitation has on self-awareness of impairment. Furthermore, other factors may explain greater levels of depression in patients in rehabilitation for a longer period of time. Since patients who reported higher levels of depression also had a mean CES-D score of 24, they fulfilled the CES criteria for clinical depression. According to previous research [20-21], depression following vision loss often represents an additional source of disability or barrier to functioning. Therefore, patients' extended rehabilitation time may possibly be explained by the negative effect that depression can have on patients' functioning levels and rehabilitation outcomes.

\section{LIMITATIONS}

Several limitations are present in the current study, and results should be interpreted with caution. Although parametric tests revealed medium to large effect sizes in this study, the sample size is considered to be relatively small and correlation coefficients were low to moderate. In addition, the study's design is cross-sectional. Therefore, we are unable to identify causal relationship between variables and must therefore identify associations to be explored in further research. In addition, present findings reflect only these patients' perspectives and cannot be generalized to other samples without taking into account its inherent limitations.

\section{CONCLUSIONS AND IMPLICATIONS FOR PRACTICE}

Current findings draw attention to psychological variables related to depression following vision loss, particularly concerning patients' self-awareness of impairment and perceived social support. These findings suggest that depression following vision loss may be related to patients' emotional experiences of impairment and adjustment processes. This hypothesis is consistent with previous literature in that depression is an emotional state modulated by 
individuals' emotional processes (e.g., emotional awareness, processing, and experiences) [51], and some previous studies have suggested that emotion-focused coping strategies are not adaptive [25-27]. Conversely, this hypothesis would suggest a more positive role of emotion in patients' adjustment to the impairment. This hypothesis is in agreement with recent psychological approaches [51-53] that conceptualize patients' emotions as potential awareness facilitators and experience-processing promoters. Therefore, depression may be part of the adjustment process to impairment, rather than a discrete adverse outcome, such that patients may become depressed as they become more aware of their current and future limitations and perceive their own impairment in a more realistic way. Depressive symptoms may thus represent a crucial step in recovery, insofar as becoming aware of impairment is decisive in fostering further acceptance of vision loss, need for rehabilitation, and adoption of assistive devices. Nevertheless, more research is still needed on this topic. Longitudinal epidemiological mixed-methods designs may be important in further testing these relationships to the hypothesis presented here.

Regarding the implications of rehabilitation and clinical practice, this study suggests that more attention should be paid to specific psychological variables of selfawareness of impairment and perceived social support. For example, it might be relevant for rehabilitation professionals to assess and manage patients' self-awareness of impairment and perceived social support throughout the rehabilitation process. Such a strategy could help to manage how patients are coping with their own impairment and its implications. Furthermore, a psychotherapeutic process that includes the aim of facilitating patients' self-awareness of impairment and better use of social support could help patients better manage depressive levels, better accept assistive devices, cope with the impairment in a realistic way, and capitalize on the rehabilitation program.

\section{ACKNOWLEDGMENTS}

\author{
Author Contributions: \\ Study concept and design: H. Senra. \\ Acquisition of data: H. Senra. \\ Analysis and interpretation of data: C. R. Vieira, H. Senra. \\ Drafting of manuscript: C. R. Vieira, I. Leal, E. G. Nicholls. \\ Critical revision of manuscript for important intellectual content: \\ C. R. Vieira, H. Senra, E. G. Nicholls, I. Leal. \\ Statistical analysis: C. R. Vieira, H. Senra. \\ Administrative, technical, or material support: H. Senra.
}

Financial Disclosures: The authors have declared that no competing interests exist.

Funding/Support: This material was unfunded at the time of manuscript preparation.

Institutional Review: All ethical procedures, including the informed consent, were adopted according to all institutional ethical requirements. Participant Follow-Up: The authors do not plan to inform participants of the publication of this study because contact information is unavailable.

\section{REFERENCES}

1. Karlsson J. Self-reports of psychological distress in connection with various degrees of visual impairment. J Vis Impair Blind. 1998;7:483-90.

2. Brody BL, Gamst AC, Williams RA, Smith AR, Lau PW, Dolnak D, Rapaport MH, Kaplan RM, Brown SI. Depression, visual acuity, comorbidity, and disability associated with agerelated macular degeneration. Ophthalmology. 2001;108(10): 1893-1901. [PMID:11581068] http://dx.doi.org/10.1016/S0161-6420(01)00754-0

3. King E, Sarah E, Peveler R. Psychosocial needs of elderly visually impaired patients: Pilot study of patients' perspectives. Prim Care Ment Health. 2006;4:185-97.

4. Huang CQ, Dong BR, Lu ZC, Yue JR, Liu QX. Chronic diseases and risk for depression in old age: A meta-analysis of published literature. Ageing Res Rev. 2010;9(2):131-41. [PMID:19524072] http://dx.doi.org/10.1016/j.arr.2009.05.005

5. Horowitz A. Depression and vision and hearing impairments in later life. Generations. 2003;27:32-38.

6. Evans JR, Fletcher AE, Wormald RP. Depression and anxiety in visually impaired older people. Ophthalmology. 2007; 114(2):283-88. [PMID:17270678] http://dx.doi.org/10.1016/j.ophtha.2006.10.006

7. Burmedi D, Becker S, Heyl V, Wahl H, Himmelsbach I. Emotional and social consequences of age-related low vision. Vis Impair Res. 2002;4:47-71. http://dx.doi.org/10.1076/vimr.4.1.47.15634

8. O’Donnell C. The greatest generation meets its greatest challenge: vision loss and depression in older adults. J Vis Impair Blind. 2005;99:197-208.

9. Brody B, Roch-Levecq A, Kaplan R, Moutier C, Brown S. Age-related macular degeneration: self-management and reduction of depressive symptoms in a randomized controlled study. J Am Geriatr Soc. 2006;54:1557-62.

10. Bromet E, Andrade LH, Hwang I, Sampson NA, Alonso J, de Girolamo G, de Graaf R, Demyttenaere K, Hu C, Iwata N, Karam AN, Kaur J, Kostyuchenko S, Lépine J-P, Levinson D, Matschinger H, Mora ME, Browne MO, Posada-Villa J, Viana MC, Williams DR, Kessler RC. Cross-national epidemiology of DSM-IV major depressive episode. BMC Med. 
2011;9(1):90. [PMID:21791035]

http://dx.doi.org/10.1186/1741-7015-9-90

11. Upton L, Bush B, Taylor R. Stress, coping, and adjustment of adventitiously blind male veterans with and without diabetes mellitus. J Vis Impair Blind. 1998;92:656-65.

12. Crews J, Valluru B, Campbell V. The effects of comorbidites among older people with vision impairment. Int Congr Ser. 2005;1282:375-79. http://dx.doi.org/10.1016/j.ics.2005.05.141

13. Boerner K, Wang S, Cimarolli V. The impact of functional loss: nature and implications of life changes. J Loss Trauma. 2006;11:265-87. http://dx.doi.org/10.1080/15325020600662625

14. Grant P, Seiple W, Szlyk JP. Effect of depression on actual and perceived effects of reading rehabilitation for people with central vision loss. J Rehabil Res Dev. 2011;48(9): 1101-1108. [PMID:22234714] http://dx.doi.org/10.1682/JRRD.2010.05.0080

15. Owsley C, McGwin G Jr. Depression and the 25-item National Eye Institute Visual Function Questionnaire in older adults. Ophthalmology. 2004;111(12):2259-64. [PMID:15582083] http://dx.doi.org/10.1016/j.ophtha.2004.06.026

16. Nyman SR, Gosney MA, Victor CR. Psychosocial impact of visual impairment in working-age adults. Br J Ophthalmol. 2010;94(11):1427-31. [PMID:19850584]

http://dx.doi.org/10.1136/bjo.2009.164814

17. Kempen GI, Ballemans J, Ranchor AV, van Rens GH, Zijlstra GA. The impact of low vision on activities of daily living, symptoms of depression, feelings of anxiety and social support in community-living older adults seeking vision rehabilitation services. Qual Life Res. 2012;21(8):1405-11. [PMID:22090173] http://dx.doi.org/10.1007/s11136-011-0061-y

18. Fenwick EK, Pesudovs K, Khadka J, Dirani M, Rees G, Wong TY, Lamoureux EL. The impact of diabetic retinopathy on quality of life: Qualitative findings from an item bank development project. Qual Life Res. 2012;21(10): 1771-82. [PMID:22290480] http://dx.doi.org/10.1007/s11136-012-0110-1

19. Jones GC, Rovner BW, Crews JE, Danielson ML. Effects of depressive symptoms on health behavior practices among older adults with vision loss. Rehabil Psychol. 2009;54(2): 164-72. [PMID:19469606] http://dx.doi.org/10.1037/a0015910

20. Casten R, Rovner B, Edmonds S. The impact of depression in older adults with age-related macular degeneration. $\mathrm{J}$ Vis Impair Blind. 2002;96:399-408.

21. Casten R, Rovner B. Depression in age-related macular degeneration. J Vis Impair Blind. 2008;102(10):591-99. [PMID:20011131]

22. Dreer LE, Elliott TR, Berry J, Fletcher DC, Swanson M, Christopher McNeal J. Cognitive appraisals, distress and disability among persons in low vision rehabilitation. $\mathrm{Br} \mathrm{J}$ Health Psychol. 2008;13(Pt 3):449-61. [PMID:17535505] http://dx.doi.org/10.1348/135910707X209835

23. Tabrett DR, Latham K. Adjustment to vision loss in a mixed sample of adults with established visual impairment. Invest Ophthalmol Vis Sci. 2012;53(11):7227-34.

[PMID:23010637]

http://dx.doi.org/10.1167/iovs.12-10404

24. Verstraten P, Brinkmann W, Stevens N, Schouten J. Loneliness, adaptation to vision impairment, social support and depression among visually impaired elderly. Int Congr Ser. 2005;1282:317-21.

http://dx.doi.org/10.1016/j.ics.2005.04.017

25. Horowitz A, Reinhardt J. Mental health issues in vision impairment: Research in depression, disability, and rehabilitation. In: Silverstone B, Lang M, Rosenthal B, Faye E, editors. The Lighthouse handbook on vision impairment and vision rehabilitation. New York (NY): Oxford University Press; 2000. p. 1089-1109.

26. Reinhardt JP, Boerner K, Horowitz A. Personal and social resources and adaptation to chronic vision impairment over time. Aging Ment Health. 2009;13(3):367-75.

[PMID:19484600]

http://dx.doi.org/10.1080/13607860902860912

27. Garnefski N, Kraaij V, De Graaf M, Karels L. Psychological intervention targets for people with visual impairments: The importance of cognitive coping and goal adjustment. Disabil Rehabil. 2010;32(2):142-47. [PMID:19951232] http://dx.doi.org/10.3109/09638280903071859

28. Wang SW, Boerner K. Staying connected: Re-establishing social relationships following vision loss. Clin Rehabil. 2008;22(9):816-24. [PMID:18728135] http://dx.doi.org/10.1177/0269215508091435

29. Boerner K, Wang SW. How it matters when it happens: Life changes related to functional loss in younger and older adults. Int J Aging Hum Dev. 2010;70(2):163-79.

[PMID:20405588] http://dx.doi.org/10.2190/AG.70.2.d

30. Senra H, Oliveira RA, Leal I. From self-awareness to selfidentification with visual impairment: A qualitative study with working age adults at a rehabilitation setting. Clin Rehabil. 2011;25(12):1140-51. [PMID:21831925] http://dx.doi.org/10.1177/0269215511410729

31. Senra H. From the injured body to changes in self-identity: A research on adults with acquired physical impairments [dissertation]. [Lisbon, Portugal]: Instituto Superior de Psicologia Aplicada; 2011. 208 p.

32. Tashakkori A, Teddie C. Handbook of mixed methods in social and behavioral research. 2nd ed. Thousand Oaks (CA): SAGE Publications; 2010.

33. Creswell J, Clark V. Designing and conducting mixed methods research. 2nd ed. Thousand Oaks (CA): SAGE Publications; 2011. 
34. World Health Organization. ICD update and revision platform: change the definition of blindness [Internet]. Geneva (Switzerland): World Health Organization. Available from: http://www.who.int/blindness/ Change\%20the\%20Definition\%20of\%20Blindness.pdf

35. European Forum of Psychomotricity. (2004). Initial education in psychomotricity-Proposal for a minimum curriculum [Internet]. Marburg (Germany): European Forum of Psychomotricity; 2004. Available from: http://psychomot.org/wp-content/uploads/2011/10/MinimumCurriculum-english.pdf

36. Gonçalves B, Fagulha T. The Portuguese version of the Center for Epidemiologic Studies Depression Scale (CESD). Eur J Psychol Assess. 2004;20:339-48. http://dx.doi.org/10.1027/1015-5759.20.4.339

37. Bardin L. Análise de conteúdo [Content analysis]. 4th ed. Lisbon (Portugal): Edições 70; 2008. Portuguese.

38. Elo S, Kyngäs H. The qualitative content analysis process. J Adv Nurs. 2008;62(1):107-15. [PMID:18352969] http://dx.doi.org/10.1111/j.1365-2648.2007.04569.x

39. Guerra I. [Qualitative search and content analysis]. Lisbon (Portugal): Principia Editora; 2006. Portuguese.

40. Dochtermann NA, Jenkins SH. Multivariate methods and small sample sizes. Ethology. 2011;117:95-101. http://dx.doi.org/10.1111/j.1439-0310.2010.01846.x

41. Hair J, Black W, Babin B, Anderson R. Multivariate data analysis: A global perspective. 7th ed. Cranbury Township (NJ): Pearson Education; 2010.

42. Wittink MN, Barg FK, Gallo JJ. Unwritten rules of talking to doctors about depression: Integrating qualitative and quantitative methods. Ann Fam Med. 2006;4(4):302-9. [PMID:16868233] http://dx.doi.org/10.1370/afm.558

43. Henson R. Effect-size measures and meta-analytic thinking in counseling psychology research. Couns Psychol. 2006; 34:601-29. http://dx.doi.org/10.1177/0011000005283558

44. Augustin A, Sahel JA, Bandello F, Dardennes R, Maurel F, Negrini C, Hieke K, Berdeaux G. Anxiety and depression prevalence rates in age-related macular degeneration. Invest Ophthalmol Vis Sci. 2007;48(4):1498-1503.

[PMID:17389477] http://dx.doi.org/10.1167/iovs.06-0761

45. Malec J, Moessner A. Self-awareness, distress, and postacute rehabilitation outcome. Rehabil Psychol. 2000;45: 227-41. http://dx.doi.org/10.1037/0090-5550.45.3.227
46. Malec JF, Testa JA, Rush BK, Brown AW, Moessner AM. Self-assessment of impairment, impaired self-awareness, and depression after traumatic brain injury. J Head Trauma Rehabil. 2007;22(3):156-66. [PMID:17510591] http://dx.doi.org/10.1097/01.HTR.0000271116.12028.af

47. Cimarolli V. Perceived overprotection and distress in adults with visual impairment. Rehabil Psychol. 2006;51:338-45. http://dx.doi.org/10.1037/0090-5550.51.4.338

48. Tabrett DR, Latham K. Factors influencing self-reported vision-related activity limitation in the visually impaired. Invest Ophthalmol Vis Sci. 2011;52(8):5293-5302.

[PMID:21613370] http://dx.doi.org/10.1167/iovs.10-7055

49. Heyl V, Wahl H. Psychosocial adaptation to age-related vision loss: a six-year perspective. J Vis Impair Blind. 2001; 95:739-48.

50. Bragg M. Vision loss, depression and rehabilitation. International Congress Series. 2005;1282:40-41.

51. Lumley MA, Cohen JL, Borszcz GS, Cano A, Radcliffe AM, Porter LS, Schubiner H, Keefe FJ. Pain and emotion: A biopsychosocial review of recent research. J Clin Psychol. 2011;67(9):942-68. [PMID:21647882] http://dx.doi.org/10.1002/jclp.20816

52. Nesse RM, Ellsworth PC. Evolution, emotions, and emotional disorders. Am Psychol. 2009;64(2):129-39.

[PMID:19203145] http://dx.doi.org/10.1037/a0013503

53. Lumley MA. The two views of emotion in psychosomatic research. J Psychosom Res. 2010;68(3):219-21. [PMID:20159206] http://dx.doi.org/10.1016/j.jpsychores.2010.01.017

Submitted for publication August 2, 2012. Accepted in revised form March 18, 2013.

This article and any supplementary material should be cited as follows:

Senra H, Vieira CR, Nicholls EG, Leal I. Depression and experience of vision loss in group of adults in rehabilitation setting: Mixed-methods pilot study. J Rehabil Res Dev. 2013;50(9):1301-14. http://dx.doi.org/10.1682/JRRD.2012.08.0138

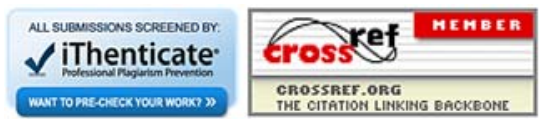


